\title{
Coronary Vasodilatory Action After a Single Dose of Nicorandil
}

\author{
HARYANTO SURYAPRANATA, MD, PATRICK W. SERRUYS, MD, \\ PIM J. DE FEYTER, MD, PIETER D. VERDOUW, PhD, \\ and PAUL G. HUGENHOLTZ, MD
}

\begin{abstract}
Coronary hemodynamics and vasodilatory effects on major epicardial arteries were investigated after a single dose of nicorandil in 22 patients undergoing cardiac catheterization for suspected coronary artery disease. Nicorandil, $20 \mathrm{mg}$, was administered sublingually to 11 consecutive patients and $40 \mathrm{mg}$ to 11 others. Systemic blood pressure decreased significantly without affecting the heart rate. Coronary sinus blood flow did not change significantly. As the mean aortic pressure decreased significantly by $13 \%$ after $20 \mathrm{mg}$ and $21 \%$ after $\mathbf{4 0} \mathrm{mg}$ of nicorandil, the calculated coronary vascular resistance decreased but did not reach statistical significance. There was a decrease in myocardial oxygen consumption $(-14 \%$ and $-22 \%$, respectively), and this was consistent with a significant decrease In the calculated pressure-rate product of $19 \%$ and $24 \%$, respectively. A total of 103 selected coronary segments, including 17 stenotic segments, were an-
\end{abstract}

alyzed quantitatively using a computer-assisted coronary angiography analysis system. After $\mathbf{2 0}$ or $\mathbf{4 0}$ $\mathrm{mg}$ of nicorandil, a significant increase of the mean diameter was observed in the proximal $(+9 \%$ and $+7 \%)$, midportion $(+10 \%$ and $+11 \%)$ and distal $(+15 \%$ and $+13 \%)$ parts of the left anterior descending coronary artery. Corresponding values for the proximal $(+13 \%$ and $+10 \%)$ and distal $(+10 \%$ and $+15 \%)$ segments of the circumflex artery were observed. An Increase in the obstruction diameter was also observed in all but 3 of the analyzed stenotic segments. The results demonstrate that nicorandil, in the route and doses used, causes a significant vasodilatation in the major eplcardial coronary segments, including most stenotic segments, and decreases the myocardial oxygen demand with little effect on the resistance vessels.

(Am J Cardiol 1988;61:292-297)
N icorandil ( $\mathrm{N}$-(2-hydroxyethyl) nicotinamide nitrate (ester)] is a potent coronary vasodilator and when administered orally, is rapidly absorbed from the mucosa of oral cavity and gastrointestinal tract. ${ }^{1,2}$ The pharmacologic profile is partly similar to that of nitroglycerin. ${ }^{3}$ Both induced similar dose-related changes in the hemodynamics and coronary circulation, ${ }^{4}$ but unlike nitroglycerin, nicorandil developed only slight tolerance in vivo, and no tolerance in vitro. ${ }^{5}$ Previous experimental and clinical data have shown that nicorandil, in dose-dependent increments, decreased peripheral

From the Thoraxcenter, University Hospital, Rotterdam, The Netherlands. Manuscript received July 13, 1987; revised manuscript received and accepted October 5, 1987.

Address for reprints: Patrick W. Serruys, MD, Catheterization Laboratory, Thoraxcenter, Erasmus University, Postbus 1738, 3000 DR Rotterdam, The Netherlands. resistance, decreased end-diastolic and end-systolic volumes and increased the coronary blood flow with little effects on myocardial oxygen consumption and atrioventricular conduction. ${ }^{1,3,4,6-12}$ The effects of nicorandil indicate a preload reduction equal to nitroglycerin and an afterload reduction approaching that of dihydralazine. ${ }^{13}$ In the nonischemic heart, nicorandil dose-dependently increases transmural left ventricular blood flow with the greatest increases occurring in the sub- and midepicardium..$^{7-9,14,15}$ It appears to act primarily by dilatation of the large coronary arteries with little effect on the myocardium., ${ }^{3,9,11,16}$

We investigated the coronary hemodynamic effects and assessed, quantitatively, the vasodilatory effect on the epicardial vessels after a single dose of nicorandil. A computer-assisted coronary angiography analysis system was used to quantify changes in the coronary diameters. 


\section{Methods}

Patients: The study population consisted of 22 patients (19 men and 3 women), undergoing cardiac catheterization for the investigation of suspected coronary artery disease. The mean age was 54 years (range 39 to 68 ). All were in sinus rhythm, none had signs of cardiac failure and all gave informed consent to participate in the study. The effects of 2 different dosages of nicorandil were investigated; nicorandil $20 \mathrm{mg}$ (group 1) was given sublingually to 11 consecutive patients and $40 \mathrm{mg}$ (group 2) to 11 others. Clinical and angiographic data are summarized in Table I. The groups were comparable with respect to age, degree of coronary artery disease, resting ejection fraction and coronary sinus blood flow (unpaired Student $t$ test).

Protocol: All medications were discontinued at least 24 hours before the study. Cardiac catheterization was performed with patients in the fasting state without premedication. After a Webster thermodilution flow catheter was inserted into the coronary sinus, angiography of the right and left coronary artery was performed in standard views, including cranial and caudal angulations. The geometry of the $x$-ray gantry, and the kilovolts and milliamperes of the $x$-ray generator were acquired and recorded on-line for each angiogram. Heart rate, aortic pressures, thermodilution coronary sinus blood flow and oxygen saturation obtained simultaneously from the aorta and coronary sinus were measured in the resting state 15 minutes after coronary angiography. Nicorandil, 20 or $40 \mathrm{mg}$, was then administered sublingually and all measurements were repeated at 5, 10, 20 and 30 minutes. Left coronary angiography was repeated 30 minutes after the drug administration in all projections, corresponding to those used during control angiograms, in order to study the effect on the dimensions of the epicardial coronary arteries. All angiograms were obtained using the Judkins technique and recorded on Kodak $35-\mathrm{mm}$ cinefilm at a rate of 25 frames/s. A nonionic contrast medium (iopamidol) was injected manually.

Coronary sinus blood flow measurements and calculations: The on-line computer system assessed the coronary sinus blood flow using a constant infusion thermodilution technique. Arterial and coronary sinus blood oxygen saturation were measured spectrophotometrically ( $\left(\mathrm{Lex}-\mathrm{O}_{2}\right.$-CON, Lexington Instruments Corp.) and oxygen content calculated. Myocardial oxygen consumption was calculated as a product of coronary sinus blood flow and arterial-coronary sinus oxygen content difference. Coronary vascular resistance was derived from the ratio of the mean aortic pressure to coronary sinus blood flow.

Quantitative coronary angiography: The quantitative analysis of selected coronary segments was carried out with the computer-assisted Coronary Angiography Analysis System (CAAS), which has been described in detail previously. ${ }^{17,18}$ To analyze a coronary arterial segment in a selected frame of $35-\mathrm{mm}$ cinefilm, an optically magnified portion of the image encompassing that segment is converted into video format by mcans of a cine-video converter. The contours
TABLE I Baseline Data of Patients Receiving $20 \mathrm{mg}$ of Nicorandil (Patients 1 to 11) and $40 \mathrm{mg}$ (Patients 12 to 22)

\begin{tabular}{|c|c|c|c|c|c|c|c|c|}
\hline \multirow[b]{2}{*}{ Pt } & \multirow{2}{*}{$\begin{array}{c}\text { Age (yr), } \\
\text { Sex }\end{array}$} & \multirow[b]{2}{*}{ NYHA } & \multirow[b]{2}{*}{ PMI } & \multicolumn{4}{|c|}{ Coronary Artery Dlsease } & \multirow{2}{*}{$\begin{array}{c}\text { EF } \\
(\%)\end{array}$} \\
\hline & & & & LM & LAD & LC & Right & \\
\hline 1 & $45, M$ & II & - & - & - & - & - & 66 \\
\hline 2 & $47, M$ & III & - & - & + & - & + & 77 \\
\hline 3 & $68, M$ & II & - & - & - & - & - & 69 \\
\hline 4 & $54, F$ & II & - & - & + & - & + & 79 \\
\hline 5 & $57, M$ & II & - & - & + & - & - & 64 \\
\hline 6 & $57, M$ & II & - & - & - & + & - & 65 \\
\hline 7 & $47, M$ & II & + & - & + & - & $t$ & 63 \\
\hline 8 & 44. M & II & - & - & - & - & + & 61 \\
\hline 9 & $49, M$ & II & + & - & + & - & + & 63 \\
\hline 10 & $68, M$ & II & - & - & + & + & + & 67 \\
\hline 11 & $68, M$ & III & + & + & + & + & + & 58 \\
\hline 12 & $60, M$ & II & - & - & - & + & - & \\
\hline 13 & $58, M$ & II & - & - & - & - & - & 70 \\
\hline 14 & $54, \mathrm{M}$ & II & - & - & + & + & - & 66 \\
\hline 15 & $51, M$ & III & - & - & + & + & + & 64 \\
\hline 16 & $39, \mathrm{M}$ & II & - & - & + & - & - & 65 \\
\hline 17 & $49, F$ & II & + & - & + & + & + & 60 \\
\hline 18 & $67, F$ & II & - & - & - & + & + & 63 \\
\hline 19 & $60, \mathrm{M}$ & II & - & - & + & + & + & 72 \\
\hline 20 & $54, \mathrm{M}$ & $\|$ & - & - & + & - & - & 66 \\
\hline 21 & $48, M$ & $\|$ & + & - & - & + & - & \\
\hline 22 & $48, M$ & II & - & - & + & + & - & 75 \\
\hline
\end{tabular}

$E F=$ global ejection fraction; $L A D=$ left anterior descending coronary artery; $L C=$ left circumflexus; $L M=$ left main coronary artery; NYHA = New York Heart Association functional class; $\mathrm{PMI}=$ previous myocardial infarction.

of the vessels are detected automatically on the basis of the weighted sum of first and second derivative functions applied to the digitized brightness information. Calibration of the diameter data of the vessels in absolute values $(\mathrm{mm})$ is achieved by using the contrast catheter as a scaling device. To this end, the contours of a user-defined portion of the optimally magnified catheter (optimal magnification factor $2 \sqrt{ } 2$ ) are detected automatically and corrected for pincushion distortion caused by the image intensifier. From the contours, the vessel diameter functions (in absolute $\mathrm{mm}$ ) are determined by computing the shortest distances between the left and right contour positions. A representative analysis, with the detected contours and the diameter functions superimposed on the original video image, is shown in Figure 1. For nonobstructed coronary segments, the mean arterial diameter of the analyzed segment was computed. For obstructed segments, the minimal obstruction diameter was assessed. A total of 103 coronary segments, including 17 stcnotic segments, were selected from the study group angiograms for analysis. The fact that a limited number of stenotic lesions were analyzed in this study is due to: (1) selection was based on the technical quality of the angiograms, with clear views of the pre- and poststenotic segments; (2) orthogonal projections of the stenotic lesions were required; and (3) only repeat angiography of the left coronary artery was performed. To ensure exact reproducibility of the sequential angiographic studies, the following measures were taken. First, as mentioned, the $\mathrm{x}$-ray system was repositioned in the settings corresponding to the projections used during 
TABLE II Coronary Hemodynamics After $20 \mathrm{mg}$ of Nicorandil $(n=11)$

\begin{tabular}{|c|c|c|c|c|c|}
\hline & Control & 5 minutes & 10 minutes & 20 minutes & 30 minutes \\
\hline $\mathrm{CSBF}(\mathrm{ml} / \mathrm{min})$ & $115 \pm 12$ & $122 \pm 12$ & $123 \pm 14$ & $113 \pm 12$ & $109 \pm 12$ \\
\hline CVR $(\mathrm{mm} \mathrm{Hg} / \mathrm{ml} / \mathrm{min})$ & $1.0 \pm 0.1$ & $0.9 \pm 0.1$ & $0.9 \pm 0.1$ & $0.9 \pm 0.1$ & $0.9 \pm 0.1$ \\
\hline $\mathrm{AO} \mathrm{O}_{2}$ content $(\mathrm{ml} \%)$ & $18.6 \pm 0.4$ & $18.6 \pm 0.4$ & $18.5 \pm 0.4$ & $18.5 \pm 0.4$ & $18.5 \pm 0.4$ \\
\hline $\mathrm{CS} \mathrm{O}_{2}$ content ( $\mathrm{ml} \mathrm{\% )}$ & $9.6 \pm 0.3$ & $9.7 \pm 0.3$ & $10.2 \pm 0.4^{*}$ & $10.3 \pm 0.4^{\dagger}$ & $10.2 \pm 0.4^{*}$ \\
\hline$(\mathrm{AO}-\mathrm{CS}) \mathrm{O}_{2} \operatorname{diff}(\mathrm{ml} \%)$ & $9.0 \pm 0.4$ & $8.9 \pm 0.4$ & $8.4 \pm 0.5^{*}$ & $8.2 \pm 0.4^{\dagger}$ & $8.3 \pm 0.5^{\dagger}$ \\
\hline $\mathrm{MVO}_{2}(\mathrm{ml} / \mathrm{min})$ & $10.2 \pm 0.9$ & $10.5 \pm 0.9$ & $9.8 \pm 0.7$ & $9.0 \pm 0.8$ & $8.8 \pm 0.9$ \\
\hline $\begin{array}{l}\text { Pressure-rate } \\
\text { product }(\mathrm{mm} \mathrm{Hg} \times \text { beats } / \mathrm{min})\end{array}$ & $9,976 \pm 705$ & $9,937 \pm 835$ & $9,281 \pm 592^{*}$ & $8,901 \pm 653^{\dagger}$ & $8,097 \pm 622 \ddagger$ \\
\hline
\end{tabular}

$\mathrm{AO}=$ aorta; $\mathrm{CSBF}=$ coronary sinus blood flow $\mathrm{CVR}=$ coronary vascular resistance; $\mathrm{O}_{2}=$ oxygen; diff $=$ difference; $\mathrm{MVO}_{2}=$ myocardial oxygen consumption.

Values are expressed as mean \pm standard error of the mean. Only $p$ values $<0.05$ (vs control) are reported: * $p$ $<0.05 ;{ }^{\dagger} p<0.01 ;{ }^{\ddagger} p<0.0005$.

the baseline angiography. Second, all study cineframes to be analyzed were selected at end-diastole, to minimizc any possible foreshortening effect. Third, the user-determined beginning and endpoints of the major coronary segments between side branches were standardized according to the definitions of the American Heart Association. ${ }^{19}$ Finally, Polaroid pictures were taken of the video image with the detected contours superimposed, to ensure that the analyses were performed on the same coronary segment in the 2 consecutive angiograms.

Statistical analysis: Results are expressed as the mean \pm standard error of the mean. Analysis of variance for repeated measurements was used and when overall significance was observed, multiple compari-

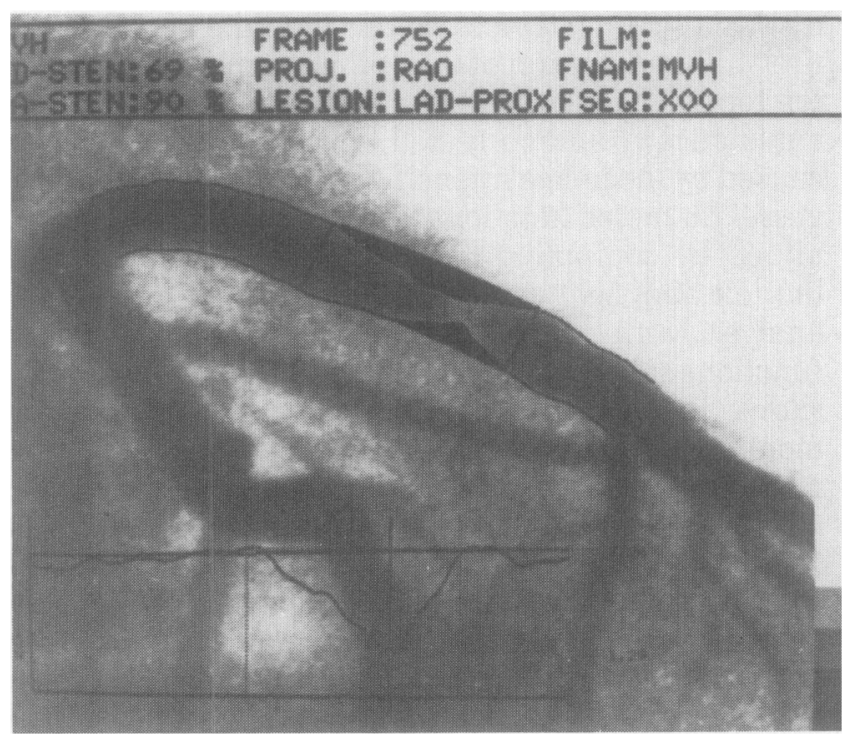

FIGURE 1. Computer output of an analyzed coronary sogment. The diameter function is superimposed on the video image; the callbrated diameter values in $\mathrm{mm}$ are plotted along the ordinate, and the centerline positions from the proximal to the distal part along the abscissa. The reference position was defined proximal of the stenotic lesion, as indicated in the diameter function by the shaded vertical bar. The central reference position is marked in the artery by a straight line connecting the opposing contour side. sons were statistically assessed with Student $t$ test. A p value of $<0.05$ was considered significant.

\section{Results}

The systemic responses after $20 \mathrm{mg}$ (group 1) and 40 $\mathrm{mg}$ (group 2) of nicorandil are summarized in Figure 2. During spontaneous heart rate, nicorandil produced a significant decrease in aortic pressures, while heart rate remained unchanged. After 30 minutes, the mean changes were $25 \mathrm{~mm} \mathrm{Hg}$ in group $1(-17 \%, \mathrm{p}<0.005)$ and $42 \mathrm{~mm} \mathrm{Hg}(-28 \%, \mathrm{p}<0.00005)$ in group 2 for the systolic aortic pressure, $7 \mathrm{~mm} \mathrm{Hg}(-9 \%, \mathrm{p}<0.005)$ and $12 \mathrm{~mm} \mathrm{Hg}(-15 \%, \mathrm{p}<0.005)$ for the diastolic aortic pressure and $14 \mathrm{~mm} \mathrm{Hg}(-13 \%, \mathrm{p}<0.005)$ and $23 \mathrm{~mm}$ $\mathrm{Hg}(-21 \%, \mathrm{p}<0.0005)$ for the mean aortic pressure, respectively.

Coronary hemodynamics: Coronary sinus blood flow did not change significantly in both groups. As the mean aortic pressure decreased significantly by $13 \%$

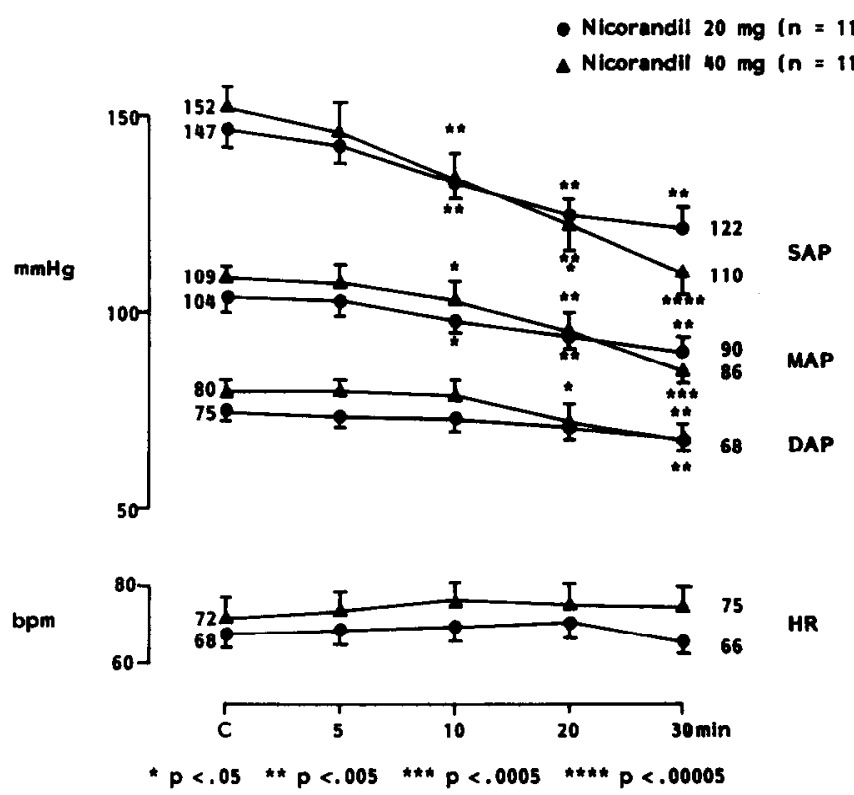

FIQURE 2. Systemic responses after administration of nicorandil. $C$ = control state; DAP = diastollc aortlc pressure; HR = heart rate; MAP = mean aortic pressure; SAP = systollc aortic pressure. 
TABLE III Coronary Hemodynamics After $\mathbf{4 0} \mathbf{~ m g}$ of NicorandII $(\mathrm{n}=\mathbf{1 1})$

\begin{tabular}{|c|c|c|c|c|c|}
\hline & Control & 5 minutes & 10 minutes & 20 minutes & 30 minutes \\
\hline CSBF $(\mathrm{ml} / \mathrm{min})$ & $93 \pm 12$ & $94 \pm 11$ & $109 \pm 13$ & $112 \pm 17$ & $92 \pm 14$ \\
\hline CVR $(\mathrm{mmHg} / \mathrm{ml} / \mathrm{min})$ & $1.3 \pm 0.2$ & $1.3 \pm 0.2$ & $1.1 \pm 0.2$ & $1.1 \pm 0.2$ & $1.1 \pm 0.2$ \\
\hline $\mathrm{AO} \mathrm{O}_{2}$ content $(\mathrm{ml} \%)$ & $18.8 \pm 0.5$ & $18.8 \pm 0.5$ & $18.8 \pm 0.5$ & $18.8 \pm 0.5$ & $18.8 \pm 0.5$ \\
\hline $\mathrm{CS} \mathrm{O}_{2}$ content $(\mathrm{ml} \%)$ & $9.5 \pm 0.5$ & $10.2 \pm 0.4$ & $10.6 \pm 0.6^{*}$ & $11.1 \pm 0.5^{\dagger}$ & $11.1 \pm 0.5^{\dagger}$ \\
\hline (AO-CS) $\mathrm{O}_{2}$ diff $(\mathrm{ml} \%)$ & $9.1 \pm 0.4$ & $8.8 \pm 0.4$ & $8.1 \pm 0.3^{*}$ & $7.6 \pm 0.3^{\ddagger}$ & $7.6 \pm 0.3^{\dagger}$ \\
\hline $\mathrm{MVO}_{2}(\mathrm{ml} / \mathrm{min})$ & $9.0 \pm 1.1$ & $8.2 \pm 1.0$ & $8.7 \pm 1.1$ & $8.5 \pm 1.3$ & $7.0 \pm 1.1^{*}$ \\
\hline $\begin{array}{l}\text { Pressure-rate } \\
\text { product }(\mathrm{mm} \mathrm{Hg} \times \text { beats } / \mathrm{min} \text { ) }\end{array}$ & $10,866 \pm 741$ & $10,824 \pm 907$ & $10,395 \pm 952$ & $9,444 \pm 908^{*}$ & $8,290 \pm 784^{\dagger}$ \\
\hline
\end{tabular}

${ }^{*} p<0.05 ;{ }^{\dagger} p<0.002 ;{ }^{\ddagger} p<0.0005$.

Abbreviations as in Table II.

after $20 \mathrm{mg}$ and $21 \%$ after $40 \mathrm{mg}$ nicorandil, the calculated coronary vascular resistance decreased but did not reach statistical significance. The mean arteriocoronary sinus oxygen content difference decreased significantly in both groups by $8 \%(\mathrm{p}<0.01)$ and by $16 \%$ $(p<0.002)$, respectively. This significant decrease in arteriocoronary sinus oxygen difference, not associated with an increase in coronary sinus blood flow, resulted in a decrease in myocardial oxygen consumption by $14 \%$ in group 1 and $22 \%$ in group 2 [Table II and III). The decrease in the myocardial oxygen consumption is consistent with a significant decrease in the calculated pressure-rate product of $19 \%$ (p $<0.0005)$ and $24 \%$ ( $\mathrm{p}<0.002$ ), respectively.

Quantitative coronary angiograms: A total of 103 coronary segments, including 17 stenotic segments, of the left coronary artery were analyzed. The mean absolute diameters (in $\mathrm{mm}$ ) of the coronary segments, as measured during the 2 consecutive angiographies, are presented in Table IV and Figure 3. Thirty minutes after $20 \mathrm{mg}$ of nicorandil, an increase of the mean diameter was observed in the proximal $1+9 \%, \mathrm{p}$ $<0.003)$, midportion $(+10 \%, \mathrm{p}<0.08)$ and distal $(+15 \%$, $\mathrm{p}<0.0006$ ) parts of the left anterior descending coronary artery. Corresponding values for the proximal and distal segments of the circumflex artery were $13 \%$ and $10 \%$ ( $p<0.003$ for each). These significant changes in the mean coronary diameter were also observed to a similar extent after $40 \mathrm{mg}$ of nicorandil. Among the 103 coronary segments analyzed, 17 stenotic segments were measured (Table V). After nicorandil, an increase in the obstruction diameter was observed in all but 3 of the stenotic lesions (Figure 3).

\section{Discussion}

The general profile of response of nicorandil, a nicotinamide nitrate (ester), is partly similar to that of the related substance, nitroglycerin. Both belong to a group of nitroesters, suggesting similar effects on the systemic and coronary hemodynamics. However, the differences between both drugs have been investigated. ${ }^{4,15,20}$ Nicorandil, unlike conventional nitrates, is probably slowly metabolized by the liver during passage through the portal system, and therefore easily enters the general circulation, resulting in greater bioavailability after oral dosing. ${ }^{2}$ Kinoshita et a ${ }^{21}$ indicated that nicorandil exerts beneficial effects on exercise capacity in patients with chronic stable angina pectoris 30 minutes after oral administration. Preliminary study has shown that plasma levels reach the highest value at that time. ${ }^{22}$

Chronotropic effect: In the route and doses used in the present study, the heart rate did not change significantly despite decreased aortic pressure. This finding is consistent with a number of animal1,3,11,12,23,24 and clinical ${ }^{25,26}$ studies. However, in a systemic and coronary hemodynamic experimental study, Mizukami et $\mathrm{al}^{4}$ demonstrated a dose-related increasc of heart rate due to a baroreflex tachycardia after an abrupt decrease in arterial pressure after administration of nicorandil. These findings were essentially consistent with the results observed in a clinical study ${ }^{6}$ In this study, all cardiac medications, including $\beta$-blockade agents, were discontinued 24 hours before catheterization. It could be speculated that some of the longer lasting effects of $\beta$-blockers may have partly contributed to

TABLE IV Effect of Nicorandll on the Absolute Coronary Artery Dlameter (mm) of All Analyzed Segments

\begin{tabular}{|c|c|c|c|c|c|c|c|c|c|c|}
\hline & \multicolumn{5}{|c|}{ Nicorandil $20 \mathrm{mg}$} & \multicolumn{5}{|c|}{ Nicorandil $40 \mathrm{mg}$} \\
\hline & $n$ & Before & After & $\Delta$ & p Value & $n$ & Before & After & $\Delta$ & p Value \\
\hline LAD-proximal & 11 & $2.42 \pm 0.19$ & $2.64 \pm 0.21$ & $+9 \%$ & 0.003 & 11 & $2.53 \pm 0.18$ & $2.71 \pm 0.20$ & $+7 \%$ & 0.002 \\
\hline LAD-mid & 6 & $2.29 \pm 0.21$ & $2.51 \pm 0.26$ & $+10 \%$ & 0.08 & 9 & $1.94 \pm 0.12$ & $2.16 \pm 0.11$ & $+11 \%$ & 0.001 \\
\hline LAD-distal & 11 & $1.84 \pm 0.10$ & $2.11 \pm 0.12$ & $+15 \%$ & 0.0006 & 11 & $1.64 \pm 0.08$ & $1.85 \pm 0.07$ & $+13 \%$ & 0.0002 \\
\hline LC-proximal & 11 & $2.44 \pm 0.16$ & $2.75 \pm 0.15$ & $+13 \%$ & 0.002 & 11 & $2.58 \pm 0.18$ & $2.85 \pm 0.18$ & $+10 \%$ & 0.00005 \\
\hline LC-distal & 11 & $2.09 \pm 0.12$ & $2.29 \pm 0.15$ & $+10 \%$ & 0.003 & 11 & $1.97 \pm 0.17$ & $2.27 \pm 0.19$ & $+15 \%$ & 0.00008 \\
\hline
\end{tabular}

Values are expressed as mean \pm standard error of the mean.

$L A D=$ left anterior descending coronary artery; $L C=$ left circumflex. 
TABLE V Effects of Nicorandil on the Stenotic Segments

\begin{tabular}{|c|c|c|c|c|c|c|}
\hline & \multicolumn{3}{|c|}{ Nicorandil $20 \mathrm{mg}(\mathrm{n}=7)$} & \multicolumn{3}{|c|}{ Nicorandil $40 \mathrm{mg}(n=10)$} \\
\hline & Before & After & $\Delta$ & Before & After & $\Delta$ \\
\hline Extent obstruction (mm) & $6.46 \pm 1.25$ & $6.92 \pm 1.35$ & $+7 \%$ & $5.03 \pm 0.45$ & $4.73 \pm 0.41$ & $-6 \%$ \\
\hline Obstruction diameter (mm) & $1.43 \pm 0.10$ & $1.58 \pm 0.13$ & $+10 \%$ & $1.29 \pm 0.14$ & $1.44 \pm 0.16$ & $+12 \%$ \\
\hline Obstruction area $\left(\mathrm{mm}^{2}\right)$ & $1.86 \pm 0.45$ & $2.20 \pm 0.60$ & $+18 \%$ & $1.34 \pm 0.27$ & $1.78 \pm 0.39$ & $+33 \%$ \\
\hline Diameter stenosis $(\%)$ & $43.1 \pm 2.8$ & $41.7 \pm 3.1$ & $-3 \%$ & $48.9 \pm 3.1$ & $41.7 \pm 4.5$ & $-15 \% *$ \\
\hline Area stenosis $(\%)$ & $70.3 \pm 4.6$ & $62.4 \pm 7.3$ & $-11 \%$ & $73.4 \pm 4.0$ & $67.7 \pm 5.0$ & $-8 \%$ \\
\hline Symmetry index & $0.47 \pm 0.10$ & $0.49 \pm 0.12$ & $+4 \%$ & $0.58 \pm 0.10$ & $0.58 \pm 0.10$ & 0 \\
\hline Reference diameter $(\mathrm{mm})$ & $2.50 \pm 0.18$ & $2.83 \pm 0.16$ & $+13 \%^{\dagger}$ & $2.22 \pm 0.11$ & $2.39 \pm 0.12$ & $+8 \%$. \\
\hline Reference area $\left(\mathrm{mm}^{2}\right)$ & $5.09 \pm 0.75$ & $6.45 \pm 0.75$ & $+27 \%^{\dagger}$ & $3.95 \pm 0.39$ & $4.57 \pm 0.43$ & $+16 \%$ \\
\hline
\end{tabular}

Values are expressed as mean \pm standard error of the mean

Only $p$ values of $<0.05$ are reported: ${ }^{*} p<0.03 ;{ }^{\dagger} p<0.005$.

the effect on heart rate and to the observed increases in coronary artery dimensions. $\beta$-blockers used alone produce a reduction in myocardial oxygen consumption, increase coronary vascular resistance and reduce coronary sinus blood flow, 27,28 which may have increased the sensitivity to the vasodilator effects of nicorandil. However, the resting heart rates of our study population suggest minimal $\beta$-blockade effect at the initiation of the study. Thus, we conclude that the observed increases in coronary dimensions are indeed the result of the administration of nicorandil.

Effect on coronary hemodynamics: Verdouw et $\mathrm{al}^{14}$ reported that after nicorandil, although left ventricular transmural blood flow was not affected, its distribution over the myocardium changed in favor of the subepicardial layers. Flow to the subendocardium decreased by $30 \%$, whereas that to the subepicardium increased by $65 \%$, which is in agreement with the observation of Preuss et al. ${ }^{15}$ As a result the endocardial-epicardial blood flow ratio decreases. However, if the decrease in aortic pressure after nicorandil is prevented by use of a cuff around the descending thoracic

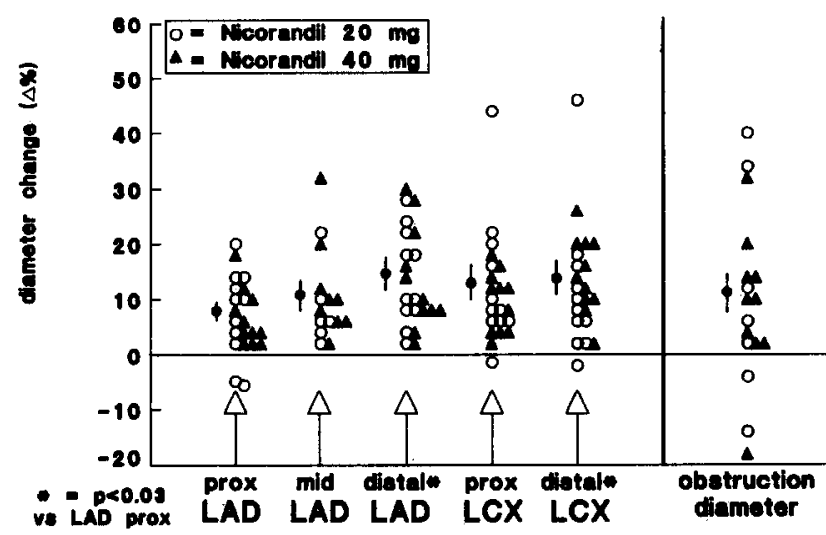

FIGURE 3. Left, percentual changes $(\Delta \%)$ In coronary artery dlameter In the proximal (prox), midportion (mid) and distal parts of the left anterlor descending (LAD), and proximal and distal parts of circumflex (LCX) coronary artery. The Increase in the coronary artery diameler was more pronounced in the distal segments when compared to the proximal segments (" $p<0.03$ vs LAD prox). Right, percentual changes $(\Delta \%)$ in the obstruction dlameter. aorta, collateral blood flow to the subendocardial layers of an ischemic area increases to a similar extent as that to the subepicardial layers. ${ }^{9,10}$ Using the intracoronary route of administration, in order to minimize systemic responses, nicorandil selectively increased epicardial blood flow suggesting a preferential susceptibility of the epicardium to the vasodilator action of nicorandil. ${ }^{14}$

The coronary sinus blood flow, as measured by thermodilution in this study, is a mixture of flow coming from the region supplied by normal and stenotic coronary artery, and the results should be interpreted with this in mind. In the doses used in this study, coronary sinus blood flow remained unchanged, despite the nicorandil-induced hypotension. Therefore, coronary vasodilation must have taken place, although the decrease in coronary vascular resistance did not reach statistical significance. There was a slight decrease in myocardial oxygen consumption $(-14 \%$ and $-22 \%$, respectively) reflected by a significant decrease in arteriocoronary sinus oxygen difference $(-8 \%$ and $-16 \%$, respectively, $p<0.01$ ), as coronary sinus oxygen content increased significantly. This was consistent with a significant decrease in the calculated pressurerate product. The finding is in agreement with an animal experimental study. ${ }^{14}$

Quantitative coronary angiography: When performing pharmacologic interventions during coronary angiography, 2 different approaches may be used: either repeated angiography in the same single view without altering the $x$-ray setting or use of multiple angiographic views. In the first case, if the coronary segment is nonaxisymmetric, induced vasodilation may accentuate the asymmetry of the lumen by preferentially relaxing the nonatherosclerotic part of the arterial wall. Consequently, the use of a single angiographic view will be misleading. It therefore follows that the effects of a vasodilatory agent will be better quantified if multiple projections are obtained. This will increase the accuracy of diameter measurements and will better reflect the true luminal cross-sectional area.

Our results demonstrate that nicorandil causes a significant vasodilatation in the normal coronary segments, as well as in the majority of the stenotic segments. In fact, the percentage of increase in the diame- 
ter of the nonobstructed segments was more pronounced in the distal segments when compared with the proximal segments as shown in Figure 3. This more pronounced distal vasodilation was also observed with other vasodilatory agents. ${ }^{29}$

Acknowledgment: The authors thank Gusta Koster and Anja van Huuksloot for their secretarial assistance in the preparation of this manuscript.

\section{References}

1. Uchida Y, Yoshimoto N, Murao S. Effect of 2-nicotamidoethyl nitrate [SG75) on coronary circulation. Ipn Heart / 1978;19:112-124.

2. Sakai $K$, Akima M Hinohara $Y$, Obatake N. Hypotensive effects and biotransformation of nicorandil, a new antianginal agent, administered to rats by different routes: comparison with nitroglycerin and isosorbide dinitrate. I Pharm Pharmacal 1984;36:175-181.

3. Sakai K, Shiraki Y, Nabata H. Cardiovascular effects of a new coronary vasodilator, $N$-(2-hydroxyethyl] nicotinamide nitrate (SG-75): comparison with nitroglycerin and dilliazem. I Cardiovasc Pharmacol 1981;3:139-150.

4. Mizukami M, Tomoike $H$, Inouh $T$, Watanabe $K$, Kikuchi $Y$, Nakamura $M$. Effects of 2-nicotinamidethyl nitrate (SG-75) and/or nitroglycerin on systemic hemodynamics and coronary blood flow in conscious dogs. Arzneimmittel Forschung 1981;31:1244-1247.

5. Nabata H, Shiraki Y, Sakai K. Development of tolerance and a new coronary vasodilator, $N$-(2-hydroxyethyl) nicotinamide nitrate (SG-75): a comparison with nitroglycerin. Jpn I Pharmacol 1981;31:511-519.

6. Belz GG, Matthews J, Heinrich J, Wagner G. Controlled comparison of the pharmacodynamic effects of nicorandil (SG-75) and isosorbide dinitrate in man. Eur / Clin Pharmacol 1984:26:681-685.

7. Lamping KA, Christensen CW, Pelc LR, Warltier DC, Gross G]. Effects of nicorandil and nifedipine on protection of ischemic myocardium. I Cardiovasc Pharmacol 1984;6:536-542.

8. Lamping KA, Warltier DC, Hardman HF, Gross GJ. Effects of nicorandil, a new antianginal agent, and nifedipine on collateral blood flow in a chronic coronary occlusion model. I Pharmacol Exp Ther 1984;229:358-363.

9. Lamping KA, Gross GJ. Comparative effects of a new nicotinamide nitrate derivative, nicorandil (SG-75), with nifedipine and nitroglycerin on true collateral blood flow following an acute coronary occlusion in dogs. I Cardiovasc Pharmacol 1984;6:601-608.

10. Lamping KA, Gross GJ. Improved recovery of myocardial segment function following a short coronary occlusion in dogs by nicorandil, a potential new antianginal agent, and nifedipine. I Cardiovasc Pharmacol 1984;7: 158-166.

11. Nakagawa Y, Takeda K, Katano Y, Tsukada T, Kitagawa T, Otorii T, Imai S. Effects of 2-nicotinamidethyl nitrate on the cardiovascular system. Jpn Heart I 1979;20:881-895.

12. Taira N, Satoh K, Yanagisawa T, Imai Y, Hiwatari M. Pharmacological profile of a new coronary vasodilator drug, 2-nicotinamidethyl nitrate [SG75). Clin Exp Pharmacol Physiol 1979:6:301-316.

13. Belz GG, Matthews JH, Beck A, Wagner G, Schneider B. Hemodynamic effects of nicorondil, isosorbide dinitrate, and dihydralazine in healt hy volunteers. I Cardiovasc Pharmacol 1985;7:1107-1112.
14. Verdouw PD, Sassen LMA, Duncker DJ, Schmeets IOL, Rensen RJ, Saxena PR. Nicorandil-induced changes in the distribution of cardiac output and coronary blood flow in pigs. Naunyn Schmiedeberg Arch Pharmacol 1987;336:352-358.

15. Preuss KC, Gross GJ, Brooks HL, Warltier DC. Hemodynamic actions of nicorandil, a new antianginal agent, in the conscious dog. / Cardiovasc Pharmacol 1985;7:709-714.

16. Imai $S$, Takeda $K$, Nakazawa $M$, Ushijinna $T$, Nabata $H$. Relaxation of the large coronary artery by nicorandil and mechanism thereof. Fed Proc 1982;41:1766.

17. Reiber JHC, Kooijman CJ, Slager CJ, Gerbrands JJ, Schuurbiers JCH, den Boer A, Wijns W, Serruys PW, Hugenholtz PG. Coronary artery dimensions from cineangiograms: methodology and validations of a computer-assisted analysis procedure. IEEE Trans Med Imaging 1984:3:131-141.

18. Reiber JHC, Serruys PW, Kooijman CI, Wijns W, Slager CI, Gerbrands II, Schuurbiers JCH, den Boer A. Hugenholtz PG. Assessment of short-, mediumand long-term variations in arterial dimensions from computer-assisted quantitation of coronary cineangiograms. Circulation 1985;71:280-288.

19. Austen WG, Edwards JE, Frye RL, Gensini GG, Gott VL, Griffith LSC, McGoon DC, Murphy ML, Roe BB. A reporting system on patients evaluated for grading of coronary artery disease. Report of the ad hoc committee for grading of coronary artery disease. Council on Cardiovascular Surgery, American Heart Association. Circulation 1975;51:7-40.

20. Shibata S, Satake N, Takagi T, Kerfoot $F$, Suh TK. Reloxing effect of nicorandil ( $N$-2 (hydroxyethyl)- nicotinamide nitrate), a new anti-angina agent, on the isolated vascular smooth muscle. Eur / Pharmacol 1984;99:219226.

21. Kinoshita M, Nishikawa S, Sawamura M, Yamaguchi S, Mitsunami K, Itoh M, Motomura M, Bito K, Mashiro I, Kawakita S. Comparative efficacy of high-dose versus low-dose nicorandil therapy for chronic stable angina pectoris. Am I Cardiol 1986;58:733-738.

22. Nakaya H, Kanda K, Oyama Y, Satoh T. Pharmaco-kinetics and hemodynamic effects of $S G-75$ (2-nicotinamide ethyl nitrate). Ipn I Clin Pharmacol 1979;10:116-118.

23. Shiraki Y, Akima M, Nabata H, Ohba Y, Hoshino E, Sakai K. The hypotensive mechanisms of the new anti-anginal drug, $N$-\{2-hydroxyethyl nicotinamide nilrate (SG-75) in beagle dogs. Ipn I Phurmacol 1981;31:921-929.

24. Sakanashi M, Yoshikawa Y, Iwasaki K, Takeo S, Araki H, Tomomatsu E, Furukawa T, Sakamoto K, Takenaka F. Effects of 2-nicotinamidethyl nitrate (SG-75) on cardiac function and myocardial metabolism of the dog. OyoYakuri 1978;15:385-389.

25. Kinoshita S, Hayashi Y, Sasaki H, Yoshida O, Ishida K, Yanagihara K, Tsuchiya T. Clinical evaluation of the new antianginal drug SG-75. Ipn J Clin Exp Med 1981;58:3429-3437.

26. Itoh $H$, Itoh $H$, Nakamura $S$, Nanasato $M$, Kirigaya $H$, Inada $M$, Korenaga M, Kanayama M, Taniguchi K. Hemodynamic effects of SG-75 in acute myocardial infarction: comparison with nitroglycerin. Ipn I Clin Pharmacol 1982;13:43-44.

27. Schang SJ, Pepine C]. Effects of propranolol on coronary hemodynamic and metabolic responses to tachycardia stress in patients with and without coronary disease. Cathet Cardiovasc Diagn 1977;3:47-67.

28. Schang SJ, Pepine CJ. Coronary and myocardial metabolic effects of combined glyceryl-trinitrate and propranolol administration. Br Heart I 1978:40:1221-1228.

29. Schulz W, Wendt T, Scherer D, Kober G. Diameter changes of epicardial coronary arteries and coronary stenoses after intracoronary application of Sin 1, a molsidomine metabolite. Z Kardiol 1983:72:404-409. 